Research article

Open Access

\title{
The combined immunodetection of AP-2 $\alpha$ and YY1 transcription factors is associated with ERBB2 gene overexpression in primary breast tumors
}

\author{
Abdelkader Allouche ${ }^{1}$, Gregory Nolens², Annalisa Tancredi ${ }^{3}$, Laurence Delacroix², Julie Mardaga1, \\ Viviana Fridman ${ }^{1}$, Rosita Winkler ${ }^{2}$, Jacques Boniver ${ }^{1}$, Philippe Delvenne ${ }^{1}$ and \\ Dominique $Y$ Begon 1,2
}

\begin{abstract}
1'Department of Pathology, GIGA-Research, CRCE, University of Liege and CHU of Liege, B23, Avenue de l'Hopital, 3, 4000 Liege, Belgium 2Molecular Oncology Laboratory, GIGA-Research, CRCE, University of Liege, B34, Avenue de I'Hopital, 1, 4000 Liege, Belgium

${ }^{3}$ Department of Public Health, Epidemiology and Health Economics, University of Liege, B23, Avenue de l'Hopital, 3, 4000 Liege, Belgium
\end{abstract}

Corresponding author: Dominique Y Begon, D.Begon@ulg.ac.be

Received: 18 Jul 2007 Revisions requested: 3 Sep 2007 Revisions received: 17 Dec 2007 Accepted: 24 Jan 2008 Published: 24 Jan 2008

Breast Cancer Research 2008, 10:R9 (doi:10.1186/bcr1851)

This article is online at: http://breast-cancer-research.com/content/10/1/R9

(C) 2008 Allouche et al.; licensee BioMed Central Ltd.

This is an open access article distributed under the terms of the Creative Commons Attribution License (http://creativecommons.org/licenses/by/2.0), which permits unrestricted use, distribution, and reproduction in any medium, provided the original work is properly cited.

\begin{abstract}
Introduction Overexpression of the ERBB2 oncogene is observed in about $20 \%$ of human breast tumors and is the consequence of increased transcription rates frequently associated with gene amplification. Several studies have shown a link between activator protein 2 (AP-2) transcription factors and ERBB2 gene expression in breast cancer cell lines. Moreover, the Yin Yang 1 (YY1) transcription factor has been shown to stimulate AP-2 transcriptional activity on the ERBB2 promoter in vitro. In this report, we examined the relationships between ERBB2, AP-2 $\alpha$, and $Y Y 1$ both in breast cancer tissue specimens and in a mammary cancer cell line.
\end{abstract}

Methods ERBB2, AP-2 $\alpha$, and YY1 protein levels were analyzed by immunohistochemistry in a panel of 55 primary breast tumors. ERBB2 gene amplification status was determined by fluorescent in situ hybridization. Correlations were evaluated by a $\chi^{2}$ test at a $p$ value of less than 0.05. The functional role of AP$2 \alpha$ and $Y Y 1$ on ERBB2 gene expression was analyzed by small interfering RNA (siRNA) transfection in the BT-474 mammary cancer cell line followed by real-time reverse transcriptionpolymerase chain reaction and Western blotting.
Results We observed a statistically significant correlation between ERBB2 and AP- $2 \alpha$ levels in the tumors $(p<0.01)$. Moreover, associations were found between ERBB2 protein level and the combined high expression of AP-2 $\alpha$ and YY1 $(p<$ 0.02 ) as well as between the expression of AP-2 $\alpha$ and $Y Y 1$ ( $p$ $<0.001)$. Furthermore, the levels of both AP- $2 \alpha$ and YY1 proteins were inversely correlated to $E R B B 2$ gene amplification status in the tumors $(p<0.01)$. Transfection of siRNAs targeting AP- $2 \alpha$ and AP- $2 \gamma$ mRNAs in the BT-474 breast cancer cell line repressed the expression of the endogenous $E R B B 2$ gene at both the mRNA and protein levels. Moreover, the additional transfection of an siRNA directed against the YY1 transcript further reduced the ERBB2 protein level, suggesting that AP-2 and $Y Y 1$ transcription factors cooperate to stimulate the transcription of the ERBB2 gene.

Conclusion This study highlights the role of both AP-2 $\alpha$ and YY1 transcription factors in ERBB2 oncogene overexpression in breast tumors. Our results also suggest that high ERBB2 expression may result either from gene amplification or from increased transcription factor levels.

\section{Introduction}

The ERBB2 oncogene (also known as HER2) belongs to the epidermal growth factor receptor gene family and encodes a $185-\mathrm{kDa}$ receptor tyrosine kinase [1]. The ERBB2 gene is overexpressed in several human tumors, mostly in breast and ovary carcinomas, where the overexpression is a marker of poor prognosis [2]. Moreover, ERBB2 gene overexpression is able to transform cells in culture and to induce mammary tumors in transgenic mice [3]. ERBB2 gene-overexpressing tumors are more aggressive due to increased invasive,

AP-2 = activator protein 2; ASCO = American Society of Clinical Oncology; CAP = College of American Pathologists; ChIP = chromatin immunoprecipitation; FISH = fluorescent in situ hybridization; IHC = immunohistochemistry; RT-PCR = reverse transcription-polymerase chain reaction; siRNA = small interfering RNA; YY1 = Yin Yang 1. 
metastatic, and angiogenic phenotypes [4]. Therefore, elucidating the mechanisms leading to ERBB2 gene overexpression is an important step in understanding the pathogenesis of a particularly aggressive subset of breast tumors.

Several laboratories have undertaken the study of the mechanisms leading to the accumulation of high levels of ERBB2 transcript and corresponding protein in breast cancer cells. First, the overexpression of the ERBB2 gene has been shown to be partly explained by gene amplification [5]. However, in breast cancer cell lines, regardless of whether the gene is amplified, there is a higher ERBB2 mRNA level per gene copy in overexpressing tumor cells compared with cells with a low ERBB2 expression [6,7]. In addition, we and others have demonstrated that $E R B B 2$ overexpression is due to increased transcription rates and not to the stabilization of the mRNA $[6,8]$. Further experiments, therefore, were needed to identify the activating sequences in the ERBB2 promoter, and the molecules that bind them, such as the activator protein 2 (AP2) transcription factors.

The AP-2 family currently includes five related $50-k D a$ proteins: AP- $2 \alpha$, AP- $2 \beta$, AP- $2 \gamma$ [9], AP- $2 \delta$ [10], and AP- $2 \varepsilon$ [11]. Several in vitro and in vivo sets of data have demonstrated a connection between AP-2 transcription factors and ERBB2 expression. First, four AP-2 binding sequences were identified in the ERBB2 promoter [12-15]. Then, we reported the in vivo binding of AP-2 proteins to these sites on the endogenous $E R B B 2$ promoter by chromatin immunoprecipitation (ChIP) experiments $[13,16]$. Moreover, in vitro results of transfection experiments have shown that AP-2 factors contribute significantly to the activity of the ERBB2 promoter [9,12-16]. In particular, expression of a dominant negative AP-2 protein in mammary cancer cells was shown to result in the inhibition of the transcription from a reporter vector bearing a $6-\mathrm{kb}$ fragment of the ERBB2 promoter [13]. Finally, AP-2 transcription factors have been shown to be highly expressed in breast cancer cell lines overexpressing ERBB2 [9,14].

AP-2 factors modulate transcription through interactions with several nuclear factors (for example, PARP [17], PC4 [18], CITED2 [19], CITED4 [20], and p300 [21]). Recently, we identified Yin Yang 1 (YY1) as a new cofactor stimulating AP2 transcriptional activity [16]. YY1 is a multifunctional transcription factor that modulates the expression of a wide variety of genes [22]. It can act as a transcriptional activator or repressor, depending on the context of its binding site within a particular promoter [23] and on other cell type-specific factors [24]. A wide variety of proteins are able to bind to YY1, indicating that protein-protein interactions are important for its activity. Among these proteins, YY1 interacts with AP- $2 \alpha$ through a domain highly conserved in AP-2 $\gamma$ [25]. Moreover, YY1 enhances AP-2 $\alpha$, AP-2 $\beta$, and AP- $2 \gamma$ transcriptional activity on the ERBB2 promoter in breast cancer cells [16]. ChIP experiments also showed that the $\mathrm{YY} 1$ protein is recruited on the endogenous $E R B B 2$ promoter only when a member of the AP-2 protein family is present [16].

The aim of this study was to characterize better the relationship between the overexpression of ERBB2 oncogene and AP- $2 \alpha$ transcription factor in primary breast tumors and to determine whether the expression level of the YY1 cofactor could play a role in the association between the expression of AP- $2 \alpha$ and ERBB2. In this study, we first demonstrated that the expression of these proteins is positively correlated in breast cancer tissues. These results were further associated with ERBB2 gene amplification status and then corroborated by a functional analysis using small interfering RNA (siRNA) transfected in a mammary cancer cell line. Altogether, our data indicate that $E R B B 2$ gene amplification or increased levels of transcription factors may lead to a pathologically high level of ERBB2 transcript and protein in breast cancer.

\section{Materials and methods Tissue samples}

A series of 55 primary tumors from breast cancer patients diagnosed between 2002 and 2004 at the University Hospital of Liege, Belgium, was analyzed. The mean age of the patients was 61.9 years and the median was 59.0 years (range: 38.0 to 88.0 years). The clinicopathological data of the patients are summarized in Table 1. The tumor samples were fixed in $10 \%$ buffered formalin and embedded in paraffin. The histological diagnosis was confirmed by reviewing the original sections of the primary tumors. All of the tumors were simultaneously evaluated for histological type and grade by senior pathologists. The most representative blocks were selected and cut into new 5- $\mu$ m-thick sections for immunohistochemical analyses. The study was approved by the local ethics committee at the Liege University Hospital.

\section{Immunohistochemistry}

Sections of breast biopsy specimens underwent immunoperoxidase staining using antibodies directed against AP- $2 \alpha$ (1:100) (\#39001; Active Motif, Carlsbad, CA, USA), against YY1 (1:50) (H-10; Santa Cruz Biotechnology, Inc., Santa Cruz, CA, USA), or against ERBB2 (1:250) (A0485; Dako A/ $S$, Glostrup, Denmark). The sections were deparaffinized in xylene and rehydrated in methanol. Endogenous peroxidases were blocked by $5 \% \mathrm{H}_{2} \mathrm{O}_{2}$ treatment. For better antigen retrieval, the samples were boiled either in a microwave oven for $3 \times 5$ minutes in citrate buffer (AP-2 $\alpha$ and $\mathrm{YY} 1)$ or in a water bath at $99^{\circ} \mathrm{C}$ in EDTA (ethylenediaminetetraacetic acid) buffer for 40 minutes (ERBB2). Samples were then washed with phosphate-buffered saline-Tween $(\mathrm{pH} 7.2 ; 1.5 \%)$ and incubated with the primary antibody at room temperature for 30 minutes (AP-2 $\alpha$ and $Y Y 1$ ) or 1 hour (ERBB2). After washings, the revelation was performed with the use of appropriate secondary antibodies and the LSAB2 system (AP-2 $\alpha$ and YY1; Dako A/S) or the EnVision kit (ERBB2; Dako A/S) according to the supplier's recommendations. Immunoreactiv- 
Table 1

\begin{tabular}{|c|c|c|c|c|c|c|c|}
\hline \multirow{3}{*}{$\begin{array}{l}\text { Characteristic } \\
\text { Number of patients }\end{array}$} & \multirow{3}{*}{$\begin{array}{c}n \\
55\end{array}$} & \multirow{3}{*}{$\begin{array}{c}\text { (Percentage) } \\
(100)\end{array}$} & \multicolumn{4}{|c|}{ ERBB2 expression (percentage) } & \multirow[t]{3}{*}{$P$ value } \\
\hline & & & \multicolumn{2}{|c|}{$(0 / 1+/ 2+)$} & \multicolumn{2}{|c|}{$(3+)$} & \\
\hline & & & 40 & (73) & 15 & $(27)$ & \\
\hline Tumor size & & & & & & & NS \\
\hline $\mathrm{T}_{1}$ & 20 & (36) & 16 & (80) & 4 & (20) & \\
\hline $\mathrm{T}_{2}$ & 29 & (53) & 20 & (69) & 9 & (31) & \\
\hline $\mathrm{T}_{3}$ & 6 & (11) & 4 & $(67)$ & 2 & (33) & \\
\hline Lymph node status & & & & & & & NS \\
\hline Negative & 33 & $(60)$ & 24 & (73) & 9 & $(27)$ & \\
\hline Positive & 22 & $(40)$ & 16 & (73) & 6 & $(27)$ & \\
\hline \multicolumn{8}{|l|}{ Grade } \\
\hline Not determined & 3 & (5) & / & & & & \\
\hline 1 & 12 & $(22)$ & 29 & (83) & 6 & $(17)$ & 0.060 \\
\hline II & 23 & $(42)$ & & & & & \\
\hline III & 17 & (31) & 10 & $(59)$ & 7 & $(41)$ & \\
\hline Histological type & & & & & & & NS \\
\hline Ductal & 40 & (73) & 28 & (70) & 12 & (30) & \\
\hline Lobular & 7 & (13) & 5 & $(71)$ & 2 & (29) & \\
\hline Other & 8 & (14) & 7 & $(87)$ & 1 & (13) & \\
\hline ER status & & & & & & & 0.035 \\
\hline Positive & 42 & (76) & 34 & $(81)$ & 8 & (19) & \\
\hline Negative & 13 & (24) & 6 & $(46)$ & 7 & $(54)$ & \\
\hline PR status & & & & & & & 0.022 \\
\hline Positive & 32 & (58) & 27 & $(84)$ & 5 & $(16)$ & \\
\hline Negative & 23 & (42) & 13 & $(57)$ & 10 & $(43)$ & \\
\hline Menopausal status & & & & & & & NS \\
\hline Premenopausal & 9 & (16) & 8 & (89) & 1 & $(11)$ & \\
\hline Postmenopausal & 46 & (84) & 32 & (70) & 14 & (30) & \\
\hline Ki67 & & & & & & & 0.018 \\
\hline Low & 29 & (53) & 25 & $(86)$ & 4 & $(14)$ & \\
\hline High & 26 & $(47)$ & 15 & $(58)$ & 11 & $(42)$ & \\
\hline
\end{tabular}


Breast Cancer Research Vol 10 No 1 Allouche et al.

Table 1 (Continued)

Clinicopathological data of the patients and their relationships with ERBB2 expression

$\begin{array}{rcccccc}\text { p53 } & & & & & & \\ \text { Low } & 46 & (84) & 36 & (78) & 10 & (22) \\ \text { High } & 9 & (16) & 4 & (44) & 5 & (56)\end{array}$

ER, estrogen receptor; grade, Elston-Ellis modification of Bloom grade; NS, not significant; PR, progesterone receptor.

ity was visualized by a treatment with diaminobenzidine (Sigma-Aldrich, St. Louis, MO, USA), and the slides were counterstained with Mayer's hematoxylin.

For statistical analyses of AP-2 $\alpha$ and $\mathrm{YY} 1$ immunoreactivity, the percentage distribution of stained tumor cell nuclei in the sample was divided into low $(<80 \%)$ or high $(\geq 80 \%)$ expression groups according to Pellikainen and colleagues [26]. ERBB2 scoring was performed according to the recently proposed guidelines from the American Society of Clinical Oncology (ASCO) and the College of American Pathologists (CAP) [27]. Pathological ERBB2 overexpression (3+) was detected in $27 \%$ of tumors. There was a significant statistical association between ERBB2 overexpression and Ki67 immunostaining, and an inverse relationship was demonstrated with estrogen receptor and progesterone receptor status (Table 1). Furthermore, a trend toward a direct link between ERBB2 overexpression and both p53 expression and histological grade III was observed.

\section{Fluorescent in situ hybridization}

Fluorescent in situ hybridization (FISH) was performed with the INFORM HER-2/neu probe (approved by the U.S. Food and Drug Administration) and the BenchMark XT automated system (Ventana Medical Systems, Inc., Tucson, AZ, USA) according to the supplier's recommendations. A minimum of 50 cell nuclei were counted, and gene amplification was considered as present when an average of more than six ERBB2 gene copies per cell was observed [27].

\section{Statistics}

The statistical analyses were carried out with a $\chi^{2}$ test for categorical variables at a $p$ value of less than 0.05 for significance by using Statistica software (StatSoft, Inc., Tulsa, OK, USA).

\section{Cell line}

The BT-474 human mammary carcinoma cells were purchased from the American Type Culture Collection (Manassas, VA, USA) and cultured in the RPMI 1640 medium supplemented with $10 \%$ ( $\mathrm{vol} / \mathrm{vol}$ ) fetal bovine serum, $2 \mathrm{mM}$ glutamine, and $100 \mu \mathrm{g} / \mathrm{mL}$ penicillin/streptomycin (all from Cambrex Bio Science Verviers S.p.r.l., Verviers, Belgium).

\section{Small interfering RNAs}

Cells were transfected (a) on days 0 and 2 by 150 nM siRNA directed against AP- $2 \alpha$ and/or AP- $2 \gamma$ transcripts as indicated or (b) on day 0 by $30 \mathrm{nM}$ siRNA against $Y Y 1$, or $100 \mathrm{nM}$ com- bined siRNAs against AP- $2 \alpha$ and AP- $2 \gamma$ transcripts, or both as indicated. As control, cells were transfected by either an siRNA against luciferase mRNA [28] or a negative control siRNA OR-0030-neg05 from Eurogentec S.A. (Seraing, Belgium). Total RNA was extracted after 2 to 4 days of treatment. Real-time reverse transcription-polymerase chain reaction (RT-PCR) for AP-2 $\alpha$, AP- $2 \gamma$, ERBB2, and $\beta 2$-microglobulin (standard gene) transcripts were performed on $1 \mu \mathrm{g}$ of total extracted RNA. The standardized transcript levels were reported to the values obtained in cells transfected with the control siRNA. The RT-PCR analysis was performed on an ABI Prism 7000 apparatus (Applied Biosystems, Foster City, CA, USA) using standard protocol. Western blot analysis was performed on proteins extracted after 1 or 3 days of treatment as indicated. The antibodies used for Western blot were $3 B 5$ for AP-2 $\alpha, 6$ E4/4 for AP- $2 \gamma, \mathrm{H}-10$ for $\mathrm{YY} 1$, and C-19 for Ku70 (all purchased from Santa Cruz Biotechnology, Inc.) and a rabbit antibody for ERBB2 (06-562; Upstate, now part of Millipore Corporation, Billerica, MA, USA). The sequences of the siRNAs and the RT-PCR primers (all purchased from Eurogentec S.A.) are presented in Table 2.

\section{Results \\ Combined high AP-2a and YY1 levels are associated with expression of ERBB2 in breast cancer tissue samples}

We first detected levels of ERBB2, AP-2 $\alpha$, and YY1 proteins by immunohistochemistry (IHC) in tumor specimens from 55 cases of breast carcinomas (Tables 1 and 3). Representative examples of the staining patterns obtained for ERBB2 receptor and the transcription factors AP- $2 \alpha$ and $Y Y 1$ are shown in Figure 1. The AP- $2 \alpha$ and YY1 proteins were detected mainly in the nuclear compartment, while cytoplasmic staining was rare and weak (Figure 1a-d). We scored the AP-2 $\alpha$ and YY1 levels as low or high regarding the percentage of stained nuclei according to Pellikainen and colleagues [26] (Figure 1). High AP- $2 \alpha$ and YY1 protein levels were seen in $42 \%$ and $45 \%$ of breast carcinomas, respectively. For ERBB2, we considered only membranous staining (Figure 1e-h). Scoring was carried out according to the ASCO/CAP guidelines [27].

We then analyzed the correlations between the levels of ERBB2, AP-2 $\alpha$, and YY1 proteins in the tumors. Our statistical analyses showed that ERBB2 expression was significantly associated with a high AP- $2 \alpha$ transcription factor level ( $p=$ 0.003) (Table 3). Accordingly, 83\% of the tumors with high AP- $2 \alpha$ level had a $2+$ or $3+\mathrm{IHC}$ score for ERBB2 protein and 
Table 2

\begin{tabular}{|c|c|c|}
\hline & Sequence 5'-3' & Location \\
\hline \multicolumn{3}{|l|}{ siRNAs } \\
\hline siAP- $2 \alpha$ ss & CCGAAUUUCCUGCCAAAGCdTdT & \\
\hline siAP- $2 \alpha$ as & GCUUUGGCAGGAAAUUCGGdTdT & \\
\hline siAP- $2 \gamma$ ss & UUAAAUAUUCUGCCACUGGdTdT & \\
\hline siAP- $2 \gamma$ as & CCAGUGGCAGAAUAUUUAAdTdT & \\
\hline siYY1 ss & GAACUCACCUCCUGAUUAUdTdT & \\
\hline siYY1 as & AUAAUCAGGAGGUGAGUUCdTdT & \\
\hline \multicolumn{3}{|l|}{ RT-PCR primers } \\
\hline AP- $2 \alpha$ forward & AGCTGAATTTCTCAACCGACAAC & 1,013 (exon 5) \\
\hline AP- $2 \alpha$ reverse & TAGCCAGGAGCATGTTTTTTCTT & 1,083 (exon 6) \\
\hline AP- $2 \gamma$ forward & CAGAAGAGCCAAATCGAAAAATG & 1,041 (exons 5-6) \\
\hline AP- $2 \gamma$ reverse & ATTCAACCCAATCTTGTCCAACTT & 1,107 (exon 6) \\
\hline ERBB2 forward & CTGAACTGGTGTATGCAGATTGC & 2,617 (exon 20) \\
\hline$E R B B 2$ reverse & TTCCGAGCGGCCAAGTC & 2,699 (exon 21) \\
\hline
\end{tabular}

as, antisense strand; RT-PCR, reverse transcription-polymerase chain reaction; siRNA, small interfering RNA; ss, sense strand.

only $17 \%$ had a low ERBB2 expression ( 0 to $1+$ ). On the other hand, $83 \%$ of the tumors with ERBB2 low expression had a low level of AP-2 $\alpha$ protein. In contrast, no association between ERBB2 and YY1 expression was observed (Table 3). How- ever, there was a significant association of ERBB2 protein level with combined overexpression of AP-2 $\alpha$ and $Y Y 1$ transcription factors $(p \leq 0.02)$ (Table 3 ). Indeed, among the 19 cases presenting high levels of both AP-2 $\alpha$ and YY1, 84\%

Figure 1

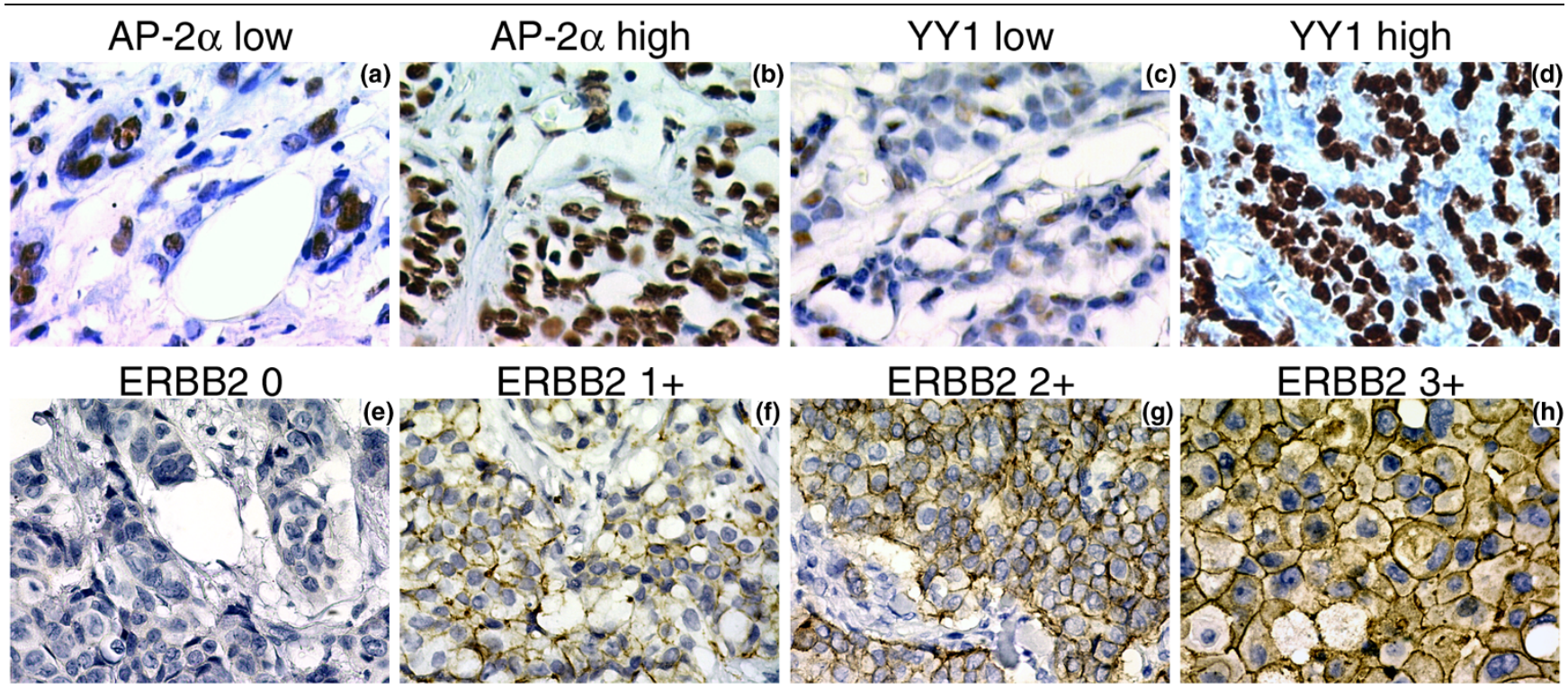

Detection of activator protein 2 alpha (AP-2 $\alpha$ ), Yin Yang 1 (YY1), and ERBB2 by immunohistochemistry in breast tumors. (a) Case with low immunoreactivity for AP-2 $\alpha$. (b) Tumor sample expressing high level of AP- $2 \alpha$ protein in more than $80 \%$ of the nuclei.(c) Tumor with low immunoreactivity for YY1. (d) Case expressing high level of YY1 protein in more than $80 \%$ of the nuclei. (e) Case with no ERBB2 membrane staining, scored as IHC 0 . (f) Tumor with partial weak membrane staining, scored as IHC 1+. (g) Case with ERBB2 score of 2+. (h) Tumor with thick circumferential ERBB2 membrane staining, scored as $\mathrm{IHC} 3+$. 
Table 3

Associations between ERBB2 and AP-2 $\alpha$ and/or YY1 levels determined by immunohistochemistry

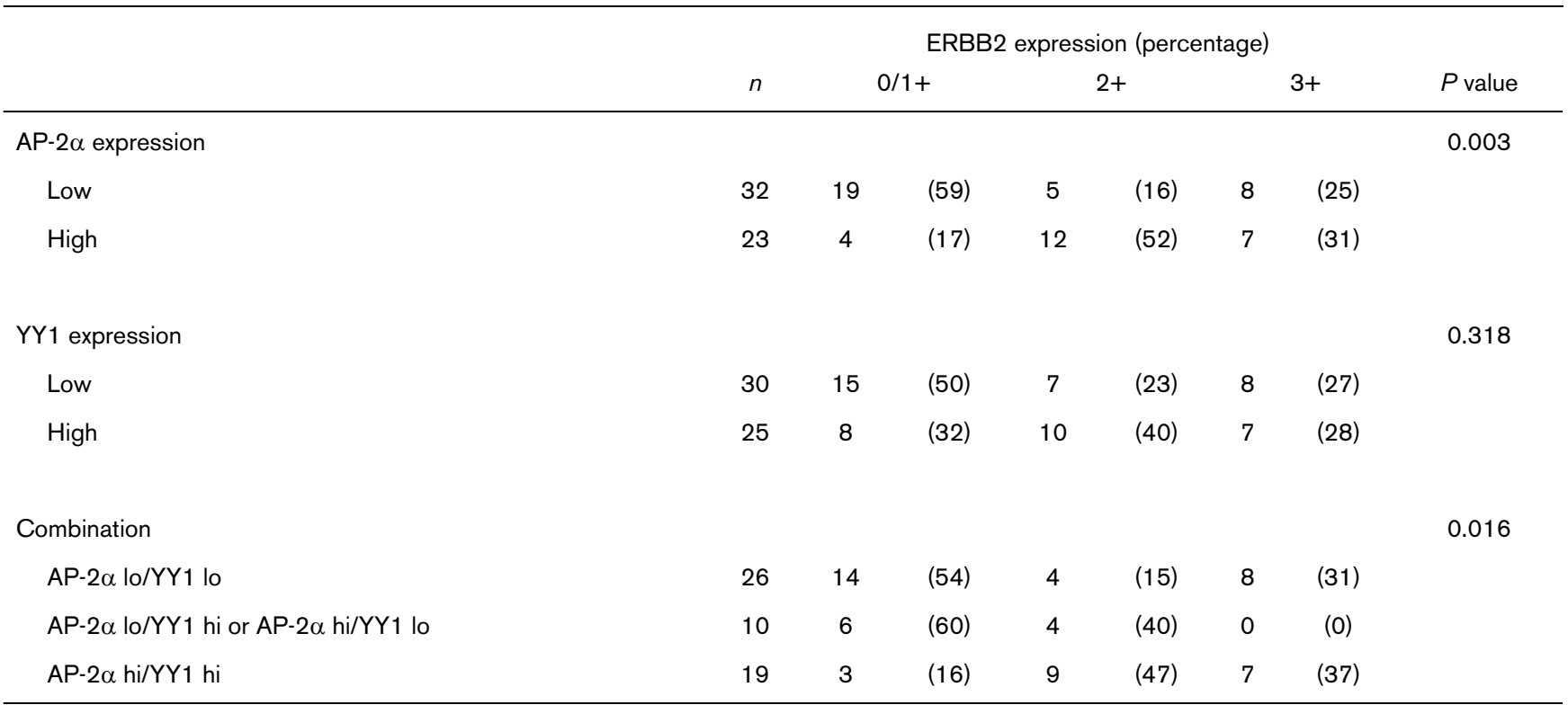

AP-2 $\alpha$, activator protein 2 alpha; hi, high expression; lo, low expression; YY1, Yin Yang 1.

had an ERBB2 $2+$ or $3+$ score (Table 3 ).

\section{Levels of both AP-2a and YY1 proteins are inversely associated with ERBB2 amplification status in primary breast cancer samples}

FISH demonstrated ERBB2 gene amplification in 11 cases of breast cancer. All of these had an ERBB2 $3+$ score in IHC. Moreover, out of the 15 ERBB2 3+ cases, 11 were FISH-positive, 2 showed no ERBB2 amplification, 1 was borderline with an average of 4 copies of ERBB2 gene per cell, and 1 was undetermined due to lack of material for FISH testing. Interestingly, the 2 cases of ERBB2 3+ immunostaining without gene amplification and the borderline case showed high AP- $2 \alpha$ and YY1 levels. On the other hand, all the ERBB2 3+ cases with low levels of both AP- $2 \alpha$ and $Y Y 1$ showed ERBB2 gene amplification. Furthermore, when considering the entire ERBB2 expressing group $(1+, 2+, 3+)$, we observed a significant inverse correlation between ERBB2 FISH status on one hand and AP-2 $\alpha$ and $Y Y 1$ levels on the other hand $(p=0.017$ and 0.029 , respectively) (Table 4 ). In particular, $80 \%$ of the cases with high levels of both AP- $2 \alpha$ and $Y Y 1$ proteins did not present ERBB2 gene amplification ( $p=0.006$ ) (Table 4). These results suggest that when the ERBB2 gene is not amplified, the $E R B B 2$ expression may rely partially on AP- $2 \alpha$ and $\mathrm{YY} 1$ transcription factor levels. Accordingly, considering only the FISH-negative cases $(n=34)$, the correlation between ERBB2 and AP- $2 \alpha$ levels was higher than in the whole group ( $r=0.67, p<0.001$ compared with $r=0.31, p$ $=0.022$ in the whole group). Interestingly, the percentage of ERBB2 2+3+/AP-2 $\alpha$-low cases decreased (12\% in the FISHnegative group compared with $24 \%$ in the entire group) (Table 5). Similarly, the percentage of ERBB2-positive/AP-2 $\alpha$-low/
YY1-low cases diminished (from 22\% in the whole group to 9\% in the FISH-negative group) (Table 5). These results indicate that high ERBB2 expression may result either from gene amplification or from increased transcription factor levels.

\section{Inhibition of AP-2 and YY1 downregulates ERBB2 expression in vitro}

After these correlation results in breast cancer specimens, we sought to study these relationships on the functional side. Although the AP-2 family is known to activate the ERBB2 promoter in reporter vectors, the effect of these transcription factors on the expression of the endogenous ERBB2 gene has not been clearly established. To find out whether AP-2 factors do contribute functionally to ERBB2 overexpression in vivo, we measured ERBB2 mRNA levels in breast cancer cells in which the expressions of AP- $2 \alpha$ and AP- $2 \gamma$ were downregulated by siRNAs. BT-474 breast cancer cells overexpressing $E R B B 2$, both through amplification and enhanced transcription, were transfected with AP- $2 \alpha$ and AP- $2 \gamma$ siRNAs, both independently and in combination for several days. Two different siRNAs against AP- $2 \alpha$ and three distinct siRNAs against AP- $2 \gamma$ were first tested (data not shown). The best one for each target, as tested by Western blotting, was further used in the study. First, AP- $2 \alpha$ and AP- $2 \gamma$ transcript levels were quantified by real-time RT-PCR in the cells transfected by the AP-2 siRNAs and reported to transfection of a control siRNA. Transfection of AP- $2 \alpha$ siRNA alone inhibited AP- $2 \alpha$ expression (Figure $2 \mathrm{a}$ ) but did not modify the AP- $2 \gamma$ transcript level (Figure 2b). Comparable results were obtained in cells transfected with AP- $2 \gamma$ siRNA alone (Figure 2a,b). Moreover, transfection of both AP- $2 \alpha$ and AP- $2 \gamma$ siRNAs induced a decrease in both mRNA levels (Figure 2a,b). Similar results were obtained the 
Inverse associations between FISH results and AP-2 $\alpha$ and/or YY1 levels in ERBB2 expressing group (1+, 2+, 3+)

\begin{tabular}{|c|c|c|c|c|c|c|}
\hline \multirow{2}{*}{ AP- $2 \alpha$ expression } & \multicolumn{6}{|c|}{ ERBB2 FISH (percentage) } \\
\hline & $n$ & \multicolumn{2}{|c|}{ Negative } & \multicolumn{2}{|c|}{ Positive } & $\begin{array}{c}P \text { value } \\
0.017\end{array}$ \\
\hline Low & 12 & 4 & (33) & 8 & $(67)$ & \\
\hline High & 18 & 15 & (83) & 3 & (17) & \\
\hline YY1 expression & & & & & & 0.029 \\
\hline Low & 14 & 6 & (43) & 8 & $(57)$ & \\
\hline High & 16 & 13 & $(81)$ & 3 & (19) & \\
\hline Combination & & & & & & 0.006 \\
\hline AP-2 $\alpha$ lo/YY1 lo & 11 & 3 & (27) & 8 & (73) & \\
\hline AP- $2 \alpha$ lo/YY1 hi or AP- $2 \alpha$ hi/YY1 lo & 4 & 4 & $(100)$ & 0 & (0) & \\
\hline AP-2 $2 \alpha$ hi/YY1 hi & 15 & 12 & $(80)$ & 3 & (20) & \\
\hline
\end{tabular}

AP-2 $\alpha$, activator protein 2 alpha; FISH, fluorescent in situ hybridization; hi, high expression; lo, low expression; YY1, Yin Yang 1.

protein level (Figure 2c, Western blotting). Markedly, 3 days after treatment with the combination of AP- $2 \alpha$ and AP- $2 \gamma$ siRNAs, both factors were undetectable (Figure 2c, lane 4), demonstrating that the siRNAs specifically inhibited the expression of their targets. We then quantified ERBB2 transcript level by real-time RT-PCR in those cells transfected by the siRNAs. Either the AP- $2 \alpha$ siRNA or the AP- $2 \gamma$ siRNA alone produced a small transient downregulation of the ERBB2 transcript level (Figure 2d). Interestingly, transfection of both AP-2 $\alpha$ and AP$2 \gamma$ siRNAs induced a significant decrease in the endogenous ERBB2 mRNA level (Figure 2d). This result was also obtained with another set of siRNAs against AP- $2 \alpha$ and AP- $2 \gamma$ (data not shown). Moreover, the inhibition was seen at the protein level (Figure 2e, lane 2). Indeed, we observed a reduction of ERBB2 protein level to $57 \%$ of control upon transfection of both siRNAs directed against AP- $2 \alpha$ and AP- $2 \gamma$. Going deeper, we further added an siRNA directed against $Y Y 1$ and observed that the ERBB2 protein level could be decreased even further to $22 \%$ of control by this combination of siRNAs (Figure 2e, lane 4). These results are strong evidence that AP2 and $Y Y 1$ transcription factors effectively participate in $E R B B 2$ expression in breast cancer cells.

\section{AP-2 and YY1 protein levels are correlated both in mammary cancer cell line and tissue specimens}

Surprisingly, we also observed a strong association between AP-2 $\alpha$ and $Y Y 1$ expression levels in the primary breast tumors $(p<0.001$ ) (Table 6). Indeed, the majority of the tumors contained either low levels ( 26 cases) or high amounts (19 cases) of both proteins. In contrast, there were only 10 cases (18\%) with a high level of either AP-2 $\alpha$ or YY1 alone (Table 6). Next, we analyzed the relationship between these factors in a breast cancer cell line. We observed that transfection of an siRNA directed against $Y Y 1$ reduced both AP-2 $\alpha$ and AP-2 $\gamma$ protein levels (Figure $2 \mathrm{e}$, lane 3 ). Additionally, the combination of siRNAs directed against both AP- $2 \alpha$ and AP- $2 \gamma$ also diminished the $Y Y 1$ protein level (Figure 2e, lane 2). These results suggest that, besides the cooperation between AP-2 and YY1 transcription factors on the $E R B B 2$ promoter, there is an intricate relationship between the expressions of these proteins.

\section{Discussion}

Multiple in vitro and in vivo data have demonstrated a link between AP-2 transcription factors and the ERBB2 oncogene. The goals of this study were to characterize better the relationship between the overexpressions of ERBB2 and AP$2 \alpha$ in primary breast tumors and to analyze the implication of the YY1 protein as a cofactor of AP-2. Although the number of tumors analyzed in this study was quite small, it should be stressed that our observations in tissue samples were further corroborated by data from the functional in vitro experiments.

Previous immunohistochemical studies on AP-2 and ERBB2 expression in primary breast tumors have reported controversial conclusions [26,29-31]. Indeed, whereas three studies showed a direct correlation between the levels of one or two AP-2 transcription factor family members and ERBB2 gene expression [26,29,31], a fourth one revealed no correlation [30]. Moreover, Turner and colleagues [31] showed that the combination of AP- $2 \alpha$ and AP- $2 \gamma$ expressions correlated to ERBB2 expression. It should be noted that these multiple studies used different antibodies which sometimes did not discriminate between the diverse members of the AP-2 family. In the present study, we focused on the AP- $2 \alpha$ member and 
Table 5

Associations between ERBB2 and AP-2 $\alpha$ and/or YY1 levels (immunohistochemistry) in the FISH-negative group

\begin{tabular}{|c|c|c|c|c|c|c|c|c|}
\hline \multirow{2}{*}{ AP-2 $\alpha$ expression } & \multicolumn{8}{|c|}{ ERBB2 expression (percentage) } \\
\hline & $n$ & \multicolumn{2}{|c|}{$0 / 1+$} & \multicolumn{2}{|r|}{$2+$} & \multicolumn{2}{|r|}{$3+$} & $\begin{array}{l}P \text { value } \\
<0.001\end{array}$ \\
\hline Low & 18 & 14 & $(78)$ & 4 & $(22)$ & 0 & (0) & \\
\hline High & 16 & 2 & $(12)$ & 11 & (69) & 3 & (19) & \\
\hline YY1 expression & & & & & & & & 0.106 \\
\hline Low & 16 & 10 & (63) & 6 & (37) & 0 & (0) & \\
\hline High & 18 & 6 & (33) & 9 & $(50)$ & 3 & (17) & \\
\hline Combination & & & & & & & & 0.015 \\
\hline AP- $2 \alpha$ lo/YY1 lo & 13 & 10 & (77) & 3 & (23) & 0 & (0) & \\
\hline AP- $2 \alpha$ lo/YY1 hi or AP- $2 \alpha$ hi/YY1 lo & 8 & 4 & $(50)$ & 4 & (50) & 0 & (0) & \\
\hline AP- $2 \alpha$ hi/YY1 hi & 13 & 2 & (15) & 8 & (62) & 3 & (23) & \\
\hline
\end{tabular}

AP-2 $\alpha$, activator protein 2 alpha; FISH, fluorescent in situ hybridization; hi, high expression; lo, low expression; YY1, Yin Yang 1.

showed a strongly significant correlation between AP-2 $\alpha$ and ERBB2 protein levels. Moreover, we demonstrated that $E R B B 2$ endogenous expression is inhibited by the downregulation of both AP- $2 \alpha$ and AP- $2 \gamma$ in a breast cancer cell line. These results and the fact that AP-2 factors bind the endogenous $E R B B 2$ gene promoter $[13,16]$ strongly suggest that AP-2 factors do effectively contribute to ERBB2 overexpression in breast cancer cells. Our siRNA results further indicate that both $\mathrm{AP}-2 \alpha$ and $\mathrm{AP}-2 \gamma$ are required for ERBB2 overexpression, as already suggested in a study on breast cancer tissues by Turner and colleagues [31].

In the present study, ERBB2 expression was also associated with combined high levels of AP- $2 \alpha$ and its partner $Y Y 1$ both in primary breast tumors, markedly in the absence of ERBB2 gene amplification, and in a breast cancer cell line. The fact that $Y Y 1$ needs AP-2 to be recruited on the endogenous ERBB2 proximal promoter [16] could explain why no direct relationship between $Y Y 1$ and ERBB2 levels was seen in the tumors and highlights the importance of the combination of high levels of AP-2 $\alpha$ and $Y Y 1$ for ERBB2 expression. To the best of our knowledge, our study is the first to report both data in primary tumors and functional results on breast cancer cells regarding the role of AP- $2 \alpha$ transcription factor and one of its cofactors on ERBB2 gene expression. Further investigations, however, are needed to determine whether breast tumors with ERBB2 2+ or 3+ IHC score without gene amplification but with high levels of AP- $2 \alpha$ and $Y Y 1$ have a particular behaviour regarding clinical outcome and response to Herceptin treatment.
Recently, Li and colleagues [32] proposed that AP-2 $\alpha$ overexpression in breast cancer cells is the consequence of a stabilization of the protein resulting from a defective proteasomal degradation, leading to an increased ERBB2 gene expression. Our results further suggest that $E R B B 2$ overexpression in breast tumors results not only from a high expression of AP$2 \alpha$ but also from the concomitant high expression of $Y Y 1$. Indeed, we have previously shown that $Y Y 1$ is able to enhance $\mathrm{AP}-2 \alpha, \mathrm{AP}-2 \beta$, and AP- $2 \gamma$ transcriptional activity in vitro and that it is recruited via AP-2 to the ERBB2 endogenous promoter in a breast cancer cell line [16]. Moreover, in the present study, we observed a strong correlation between AP- $2 \alpha$ and YY1 protein levels in the primary breast tumors and a decrease in the AP- $2 \alpha$ and AP- $2 \gamma$ levels following transfection of an siRNA targeting $Y Y 1$. These data suggest that there may be a two-sided contribution of $Y Y 1$ for ERBB2 expression. On the one hand, $Y Y 1$ increases the AP- $2 \alpha$ and AP-2 $\gamma$ protein levels, and on the other hand, YY1 stimulates AP- $2 \alpha$ and AP- $2 \gamma$ transcriptional activity. This view fits well with the additive effect of the siRNAs targeting AP-2 $\alpha$, AP- $2 \gamma$, and YY1 for inhibiting ERBB2 endogenous level.

Another finding of this study was the positive correlation between AP-2 $\alpha$ and $Y Y 1$. Interestingly, AP- $2 \alpha$ promoter is dependent upon an initiator element for proper transcription, and we noticed a potential $Y Y 1$ binding site at the transcription start site of the AP- $2 \alpha$ gene (position +4 ) [33]. Since YY1 can act as an initiator factor [24], this could explain the effect of $Y Y 1$ siRNA on the AP-2 $\alpha$ level. We also found a perfect AP2 consensus binding site on the $Y Y 1$ promoter at -236 base pairs upstream from the transcription start site [34]. Further studies are needed to determine whether these binding sites 
Figure 2

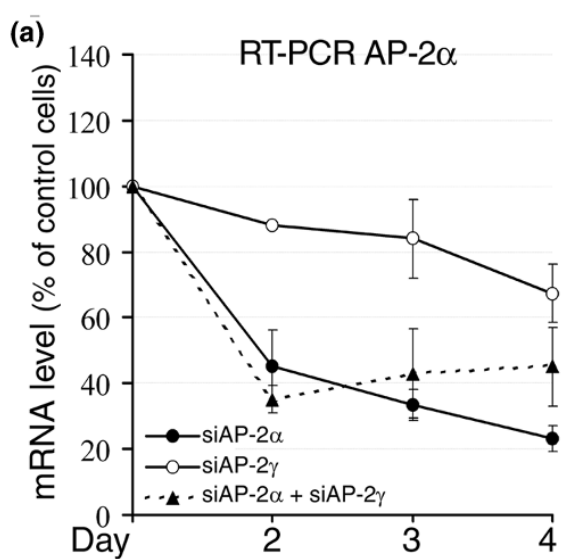

(d)

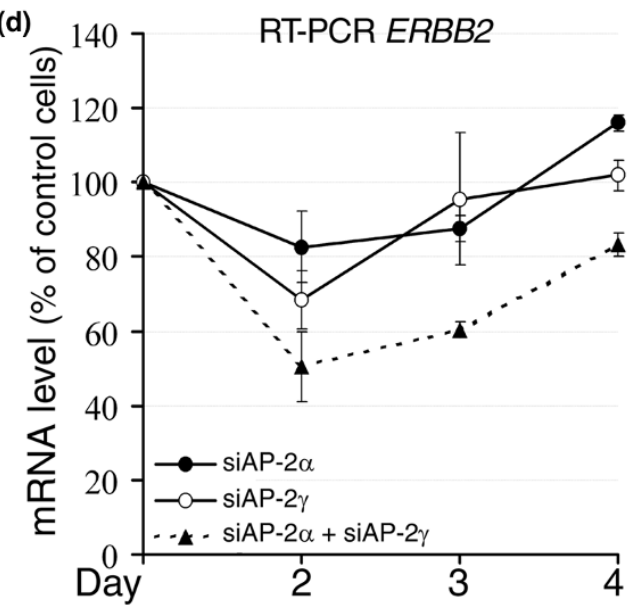

(b)

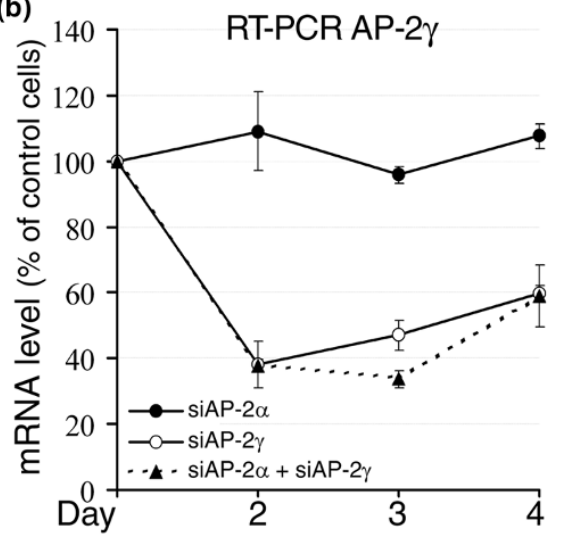

(c)

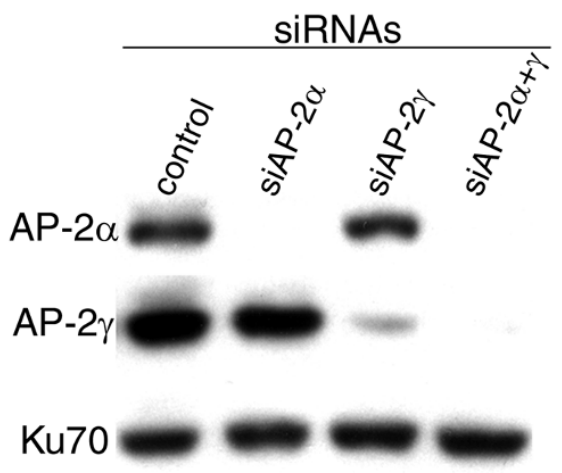

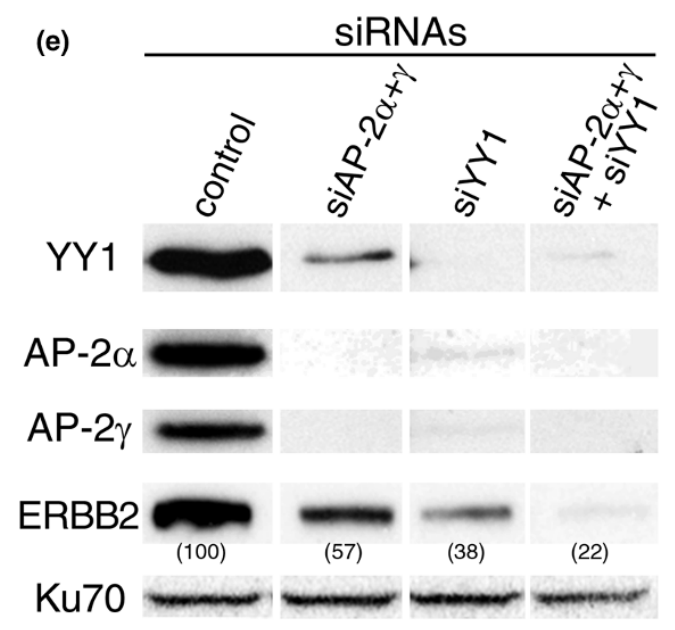

Suppression of AP-2 $\alpha$, AP- $2 \gamma$, and YY1 expression downregulates ERBB2 transcript levels in BT-474 cells. (a) Cells were transfected on days 0 and 2 by small interfering RNAs (siRNAs) directed against AP- $2 \alpha($ siAP-2 $\alpha)$ and/or AP- $2 \gamma(\operatorname{siAP}-2 \gamma)$ or against luciferase mRNA as control. Graphic shows real-time reverse transcription-polymerase chain reaction (RT-PCR) for AP- $2 \alpha$ transcripts on total RNA extracted after 2,3 , or 4 days of treatment with indicated siRNAs. Results are presented as percentages of mRNA level as compared with control cells transfected with luciferase siRNA. Data are means \pm standard deviation of three experiments. (b) RT-PCR for AP- $2 \gamma$ transcripts on total RNA. Cells were transfected like in (a). (c) Detection by Western blotting of AP-2 $\alpha$ and AP- $2 \gamma$ levels at day 3. Ku70 protein served as control. Cells were transfected like in (a).(d) RT-PCR for ERBB2 transcripts on total RNA. Cells were transfected like in (a). (e) Cells were transfected on day 0 with 30 nM siRNA directed against YY1 (siYY1) or $100 \mathrm{nM}$ combined siRNAs against AP-2 $\alpha$ and AP-2 $\gamma$ transcripts (siAP-2 $2+\gamma$ ) or both as indicated. Control cells were transfected with a commercially available negative control siRNA (contro/). Proteins extracted after 24 hours of treatment were detected by Western blotting. Ku70 protein served as control for the protein amount charged on the gel. The percentage of ERBB2 protein level compared with transfection of control siRNA is shown in brackets. AP-2, activator protein 2; YY1, Yin Yang 1.

are functional and may explain the relationship between AP- $2 \alpha$ and YY1 levels.

\section{Conclusion}

We demonstrated, for the first time, the implication of AP- $2 \alpha$ in combination with its cofactor, $Y Y 1$, in ERBB2 oncogene overexpression in breast tumors both in vitro and in breast cancer tissue specimens. Moreover, we showed that at least two mechanisms can lead to pathological ERBB2 overexpression in breast cancer: ERBB2 gene amplification and increased transcription through high levels of transcriptional activators, such as AP- $2 \alpha$ and $Y Y 1$. We hope that these data open a new way in the research field of ERBB2 overexpression and its pathogenic role in breast tumors.

\section{Competing interests}

The authors declare that they have no competing interests.

AA selected the histological specimens and performed and scored immunohistochemistry. GN performed siRNA transfection experiments and Western blotting. $A A$ and $G N$ contributed equally to this work. AT carried out the statistical analyses. LD performed siRNA transfection experiments, Western blotting, and real-time RT-PCR. JM and JB made substantial contributions to manuscript revisions. VF scored the ERBB2 immunohistochemistry. RW participated in the study design, revised the manuscript, and provided important intellectual support. PD conceived of the study, scored FISH on the histological specimens, revised the manuscript, and pro- 
Association between AP-2 $\alpha$ and YY1 levels determined by immunohistochemistry on breast tumor specimens

\begin{tabular}{|c|c|c|c|c|c|c|}
\hline & \multirow[b]{2}{*}{$n$} & \multicolumn{4}{|c|}{ AP- $2 \alpha$ expression (percentage) } & \multirow[b]{2}{*}{$P$ value } \\
\hline & & & & & & \\
\hline Low & 30 & 26 & (87) & 4 & (13) & \\
\hline High & 25 & 6 & (24) & 19 & $(76)$ & \\
\hline
\end{tabular}

AP-2 $\alpha$, activator protein 2 alpha; YY1, Yin Yang 1.

vided important intellectual support. DYB participated in the study design, coordination, and interpretation of the results and drafted and finalized the manuscript. All authors read and approved the final manuscript.

\section{Acknowledgements}

The authors thank Estelle Dortu and the Centre for Research on Prion Proteins from the University of Liege for technical assistance. This work was supported by grants from Televie (Belgium), the Leon Fredericq Foundation (Liege, Belgium), the Anticancer Centre attached to the University of Liege, and the Belgian Federation Against Cancer. AA received a mixed doctorate grant from the Belgian Directorate-General for Development Cooperation. GN, JM, and DYB are recipients of a Televie Grant from the Belgian National Fund for Scientific Research (F.N.R.S.). RW and PD are Research Directors from the F.N.R.S.

\section{References}

1. Yarden $Y$, Sliwkowski MX: Untangling the ErbB signalling network. Nat Rev Mol Cell Biol 2001, 2:127-137.

2. Klapper LN, Kirschbaum MH, Sela M, Yarden Y: Biochemical and clinical implications of the ErbB/HER signaling network of growth factor receptors. Adv Cancer Res 2000, 77:25-79.

3. Neve RM, Lane HA, Hynes NE: The role of overexpressed HER2 in transformation. Ann Oncol 2001, 12(Suppl 1):S9-13.

4. Eccles SA: The role of c-erbB-2/HER2/neu in breast cancer progression and metastasis. J Mammary Gland Biol Neoplasia 2001, 6:393-406.

5. Menard S, Casalini P, Campiglio M, Pupa S, Agresti R, Tagliabue E: HER2 overexpression in various tumor types, focussing on its relationship to the development of invasive breast cancer. Ann Oncol 2001, 12(Suppl 1):S15-S19.

6. Hollywood DP, Hurst HC: A novel transcription factor, OB2-1, is required for overexpression of the proto-oncogene c-erbB-2 in mammary tumour lines. EMBO J 1993, 12:2369-2375.

7. Kraus MH, Popescu NC, Amsbaugh SC, King CR: Overexpression of the EGF receptor-related proto-oncogene erbB-2 in human mammary tumor cell lines by different molecular mechanisms. EMBO J 1987, 6:605-610.

8. Pasleau F, Grooteclaes M, Gol-Winkler R: Expression of the cerbB2 gene in the BT474 human mammary tumor cell line: measurement of c-erbB2 mRNA half-life. Oncogene 1993, 8:849-854.

9. Bosher JM, Totty NF, Hsuan JJ, Williams T, Hurst HC: A family of AP-2 proteins regulates c-erbB-2 expression in mammary carcinoma. Oncogene 1996, 13:1701-1707.

10. Cheng $C$, Ying $K, X u M$, Zhao $W$, Zhou Z, Huang $Y$, Wang $W, X u$ $J$, Zeng $L, X i e Y$, Mao $Y$ : Cloning and characterization of a novel human transcription factor AP-2 beta like gene (TFAP2BL1). Int J Biochem Cell Biol 2002, 34:78-86.

11. Tummala R, Romano RA, Fuchs $E$ Sinha S: Molecular cloning and characterization of AP-2 epsilon, a fifth member of the AP2 family. Gene 2003, 321:93-102.

12. Bosher JM, Williams T, Hurst HC: The developmentally regulated transcription factor AP-2 is involved in c-erbB-2 overex- pression in human mammary carcinoma. Proc Natl Acad Sci U $S$ A 1995, 92:744-747.

13. Delacroix L, Begon D, Chatel G, Jackers $P$, Winkler R: Distal ERBB2 promoter fragment displays specific transcriptional and nuclear binding activities in ERBB2 overexpressing breast cancer cells. DNA Cell Biol 2005, 24:582-594.

14. Grooteclaes M, Vernimmen D, Plaza S, Pasleau F, Hodzic D, Winkler-Gol R: A new cis element is involved in the HER2 gene overexpression in human breast cancer cells. Cancer Res 1999, 59:2527-2531.

15. Vernimmen D, Begon D, Salvador C, Gofflot S, Grooteclaes M Winkler R: Identification of HTF (HER2 transcription factor) as an AP-2 (activator protein-2) transcription factor and contribution of the HTF binding site to ERBB2 gene overexpression. Biochem J 2003, 370:323-329.

16. Begon DY, Delacroix L, Vernimmen D, Jackers $P$, Winkler R: Yin Yang 1 cooperates with activator protein 2 to stimulate ERBB2 gene expression in mammary cancer cells. J Biol Chem 2005, 280:24428-24434

17. Kannan $\mathrm{P}, \mathrm{Yu} Y$, Wankhade S, Tainsky MA: PolyADP-ribose polymerase is a coactivator for AP-2-mediated transcriptional activation. Nucleic Acids Res 1999, 27:866-874.

18. Kannan P, Tainsky MA: Coactivator PC4 mediates AP-2 transcriptional activity and suppresses ras-induced transformation dependent on AP-2 transcriptional interference. $\mathrm{Mol} \mathrm{Cell}$ Biol 1999, 19:899-908

19. Bamforth SD, Braganca J, Eloranta JJ, Murdoch JN, Marques FI, Kranc KR, Farza H, Henderson DJ, Hurst HC, Bhattacharya S: Cardiac malformations, adrenal agenesis, neural crest defects and exencephaly in mice lacking Cited2, a new Tfap2 co-activator. Nat Genet 2001, 29:469-474.

20. Braganca J, Swingler T, Marques FI, Jones T, Eloranta JJ, Hurst HC Shioda T, Bhattacharya S: Human CREB-binding protein/ p300-interacting transactivator with ED-rich tail (CITED) 4, a new member of the CITED family, functions as a co-activator for transcription factor AP-2. J Biol Chem 2002, 277:8559-8565.

21. Braganca J, Eloranta JJ, Bamforth SD, lbbitt JC, Hurst HC, Bhattacharya S: Physical and functional interactions among AP-2 transcription factors, p300/CREB-binding protein, and CITED2. J Biol Chem 2003, 278:16021-16029.

22. Shi $Y$, Lee JS, Galvin KM: Everything you have ever wanted to know about Yin Yang 1. Biochim Biophys Acta 1997, 1332:F49-F66.

23. Shrivastava $A$, Calame $K$ : An analysis of genes regulated by the multi-functional transcriptional regulator Yin Yang-1. Nucleic Acids Res 1994, 22:5151-5155.

24. Thomas MJ, Seto E: Unlocking the mechanisms of transcription factor YY1: are chromatin modifying enzymes the key? Gene 1999, 236:197-208.

25. Wu F, Lee AS: YY1 as a regulator of replication-dependent hamster histone $\mathrm{H} 3.2$ promoter and an interactive partner of AP-2. J Biol Chem 2001, 276:28-34.

26. Pellikainen J, Naukkarinen A, Ropponen K, Rummukainen J, Kataja V, Kellokoski J, Eskelinen M, Kosma VM: Expression of HER2 and its association with AP-2 in breast cancer. Eur J Cancer 2004 40:1485-1495.

27. Wolff AC, Hammond ME, Schwartz JN, Hagerty KL, Allred DC, Cote RJ, Dowsett M, Fitzgibbons PL, Hanna WM, Langer A, McShane LM, Paik S, Pegram MD, Perez EA, Press MF, Rhodes A, 
Sturgeon C, Taube SE, Tubbs R, Vance GH, van de Vijver M, Wheeler TM, Hayes DF, American Society of Clinical Oncology; College of American Pathologists: American Society of Clinical Oncology/College of American Pathologists guideline recommendations for human epidermal growth factor receptor 2 testing in breast cancer. $J$ Clin Oncol 2007, 25:118-145.

28. Elbashir SM, Harborth J, Lendeckel W, Yalcin A, Weber K, Tuschl T: Duplexes of 21-nucleotide RNAs mediate RNA interference in cultured mammalian cells. Nature 2001, 411:494-498.

29. Friedrichs $N$, Jager R, Paggen E, Rudlowski C, Merkelbach-Bruse $\mathrm{S}$, Schorle H, Buettner R: Distinct spatial expression patterns of AP-2alpha and AP-2gamma in non-neoplastic human breast and breast cancer. Mod Patho/ 2005, 18:431-438.

30. Gee JM, Robertson JF, Ellis IO, Nicholson RI, Hurst HC: Immunohistochemical analysis reveals a tumour suppressor-like role for the transcription factor AP-2 in invasive breast cancer. J Pathol 1999, 189:514-520.

31. Turner BC, Zhang J, Gumbs AA, Maher MG, Kaplan L, Carter D, Glazer PM, Hurst HC, Haffty BG, Williams T: Expression of AP-2 transcription factors in human breast cancer correlates with the regulation of multiple growth factor signalling pathways. Cancer Res 1998, 58:5466-5472.

32. Li M, Wang Y, Hung MC, Kannan P: Inefficient proteasomaldegradation pathway stabilizes AP-2alpha and activates HER2/neu gene in breast cancer. Int J Cancer 2006, 118:802-811.

33. Creaser PC, D'Argenio DA, Williams T: Comparative and functional analysis of the AP2 promoter indicates that conserved octamer and initiator elements are critical for activity. Nucleic Acids Res 1996, 24:2597-2605.

34. Yao YL, Dupont BR, Ghosh S, Fang Y, Leach RJ, Seto E: Cloning, chromosomal localization and promoter analysis of the human transcription factor YY1. Nucleic Acids Res 1998, 26:3776-3783. 